\title{
Selective Kallikrein-Kinin System Activation in Inbred Rats Differentially Susceptible to Granulomatous Enterocolitis
}

\author{
R. BALFOUR SARTOR, ${ }^{*}{ }^{\ddagger}$ RAUL A. DELA CADENA, ${ }^{\S}$ KEVIN D. GREEN, ${ }^{\ddagger}$ ANTONI STADNICKI, ${ }^{\S}$ \\ STAN W. DAVIS,* JOHN H. SCHWAB,* ALBERT A. ADAM," P. RAYMOND," \\ and ROBERT W. COLMAN\$
}

Departments of ${ }^{*}$ Medicine and *Microbiology and Immunology and Center for Gastrointestinal Biology and Disease, University of North Carolina, Chapel Hill, North Carolina; ${ }^{\S}$ Sol Sherry Thrombosis Research Center, Departments of Medicine, Pathology, and Physiology, Temple University School of Medicine, Philadelphia, Pennsylvania; and "Faculty of Pharmacy, University of Montreal, Montreal, Quebec, Canada

Background \& Aims: Crohn's disease is characterized by unrestrained inflammation with a genetic component. Genetic susceptibility and activation of the kallikrein-kinin (contact) system were investigated in experimental enterocolitis and extraintestinal inflammation induced by bacterial polymers. Methods: Kinetics of inflammation in inbred Lewis and Buffalo rats injected subserosally with peptidoglycan-polysaccharide polymers were correlated with in vivo and in vitro activation of the contact system. Results: Lewis rats had a biphasic course of enterocolitis. Acute inflammation peaked 1 day after injection, gradually decreasing until day 14 when intestinal inflammation spontaneously reactivated and persisted for 16 weeks, accompanied by arthritis, granulomatous hepatitis, anemia, and leukocytosis. Self-limited acute enterocolitis in Buffalo rats resolved by 24 days without extraintestinal involvement. Consumption of the precursor proteins prekallikrein and high-molecular-weight kininogen indicated activation of the plasma contact system in Lewis rats and closely correlated with chronic intestinal inflammation. Contact system activation did not occur in Buffalo rats, even during acute inflammation. In vitro studies showed a decreased rate of kininogen cleavage in Buffalo plasma. Conclusions: Selective in vivo and in vitro activation of the contact system in susceptible Lewis rats suggests that this pathway is one determinant of genetic susceptibility to granulomatous enterocolitis and systemic complications.

C rohn's disease is characterized by chronic, spontaneously relapsing granulomatous enterocolitis associated with extraintestinal inflammation and activation of almost every limb of the inflammatory response. ${ }^{1,2}$ This idiopathic disorder shows both genetic and environmental components. Its preferential location in the distal ileum and colon, which are areas of the highest luminal bacterial colonization, and improvement when bacterial concentrations are decreased has led us to hypothesize that Crohn's disease is a genetically determined, unrestrained inflammatory response to ubiquitous luminal bacteria or bacterial components. ${ }^{2}$ Investigation of the pathogenesis of this disease has been limited by the lack of an animal model that shows a chronic, spontaneously relapsing course; transmural granulomatous inflammation; and differential genetic susceptibility in inbred rodent strains.

We have developed a rat enterocolitis model that shows these characteristics, thereby permitting detailed examination of the mechanisms of genetically determined chronic intestinal inflammation. ${ }^{3-5}$ In this model, purified peptidoglycan-polysaccharide (PG-PS) polymers are injected intramurally (subserosally) into the wall of the distal ileum, cecum, ${ }^{3,4}$ or distal colon. ${ }^{5}$ PG-PS is the primary structural component of nearly all bacteria, including those found in high concentrations within the distal ileum and colon. ${ }^{6}$ PG-PS derived from group A streptococci (PG-APS) is used as the prototype of poorly biodegradable bacterial cell wall polymers capable of inducing chronic granulomatous inflammation, although PG-PS derived from intestinal bacteria, including those isolated from patients with Crohn's disease, can also cause chronic experimental inflammation. ${ }^{6-8}$ Acute intestinal inflammation develops at the site of subserosal injection in all rat strains investigated, but chronic, granulomatous enterocolitis is restricted to certain susceptible strains. ${ }^{3,4}$ Lewis and Sprague-Dawley rats develop chronic inflammation, whereas Buffalo and Fischer $\mathrm{F}_{344}$ rats have self-limited enterocolitis with no evidence of spontaneous reactivation of inflammation. These inbred rat strains also show differential susceptibility to systemic inflammation

Abbreviations used in this paper: PG-APS, peptidoglycan-polysaccharide derived from group A streptococci; PG-PS, peptidoglycanpolysaccharide.

(C) 1996 by the American Gastroenterological Association 0016-5085/96/\$3.00 
after intraperitoneal injection of PG-APS. ${ }^{6}$ Lewis rats have spontaneous reactivation of erosive peripheral arthritis approximately 2 weeks after a single intraperitoneal injection of PG-APS, associated with hepatic granulomas and anemia, but no evidence of intestinal injury. ${ }^{6,9-11}$

Lewis rats are high responders to several other experimental inflammatory models, including adjuvant- and collagen-induced arthritis, ${ }^{12}$ indomethacin-induced enterocolitis, ${ }^{13}$ hepatobiliary inflammation associated with experimental small bowel bacterial overgrowth, ${ }^{14}$ respiratory mycoplasmosis, ${ }^{15}$ and autoimmune encephalitis. ${ }^{16}$ Two hypotheses have been advanced to explain enhanced sensitivity of Lewis rats to chronic inflammation: defective regulation of the hypothalamic/pituitary/adrenal axis ${ }^{9}$ and an abnormal balance of interleukin 1 and interleukin 1 receptor antagonist. ${ }^{4,17}$ The consequences of defective immunoregulation by either of these two mechanisms is an inappropriately aggressive inflammatory response mediated by soluble products of effector immune cells and activation of the complement and contact system cascades.

PG-APS induces the production of inflammatory mediators, such as anaphylatoxins (C3a and $\mathrm{C} 5 \mathrm{a}){ }^{18}$ eicosanoids, ${ }^{19}$ and cytokines. ${ }^{4}$ We have recently shown that intraperitoneal injection of PG-APS in Lewis rats activates the contact system, ${ }^{20}$ which results in plasma kallikrein formation and release of the inflammatory mediator bradykinin. Furthermore, we have shown that inhibition of plasma kallikrein attenuates acute PG-APS-induced arthritis. ${ }^{21}$ The plasma contact activation system comprises factor XII, factor XI, plasma prekallikrein, and high-molecular-weight kininogen and is responsible for the surface-mediated defense reactions. ${ }^{22}$ Activation of this system is characterized by conversion of plasma prekallikrein to kallikrein with a decrease in plasma prekallikrein, cleavage of high-molecular-weight kininogen by kallikrein to liberate bradykinin, and activation of factor $\mathrm{XI}$ to factor XIa, which destroys the coagulant activity of high-molecular-weight kininogen. ${ }^{23}$ Although regulatory mechanisms such as protease inhibitors and cellular clearance operate during pathological conditions, these modulating systems are not sufficient to prevent formation of its active components. Kallikrein, which results from plasma prekallikrein activation by activated factor XII, is a chemoattractant for neutrophil, ${ }^{24}$ and stimulates neutrophil aggregation ${ }^{25}$ and elastase release. ${ }^{26}$ Moreover, kallikrein hydrolyzes high-molecular-weight kininogen, which releases bradykinin, a nonapeptide that induces vasodilation, increased vascular permeability, hypotension, and intestinal chloride secretion. ${ }^{27}$

The first goal of this study was to ascertain the role of genetic susceptibility in the pathogenesis of experimental intestinal inflammation by comparing the time course of the response to intramurally injected PG-APS in two inbred rat strains: Lewis and Buffalo. A secondary objective was to determine whether the contact system participated in experimental granulomatous enterocolitis and systemic inflammation and whether it could be one of the mechanisms of the differential genetic responses. To quantify the inflammatory response, we evaluated macroscopic, histological, and biochemical indices of intestinal inflammation, hematocrits, white blood cell counts, and the presence of arthritis and hepatic granulomas. To document in vivo activation of the contact system and the systemic inflammatory response, we determined the plasma levels of plasma prekallikrein, factor XI, highmolecular-weight kininogen, $\mathrm{T}$ kininogen (the major acute-phase protein of the rat), and $\alpha_{1}$-inhibitor 3 protein (a negative acute-phase protein of the rat) ${ }^{28}$ at various time points corresponding to acute and chronic phases of inflammation. We correlated the degree of intestinal inflammation with activation of the contact system proteins. Finally, we examined in vitro activation of kallikrein and cleavage of high-molecular-weight kininogen in the two rat strains. These studies show spontaneous reactivation of enterocolitis, presence of granulomas and extraintestinal inflammation, and selective activation of the contact system in susceptible Lewis rats.

\section{Materials and Methods}

The chromogenic substrates S-2302 (kallikrein), S2366 (factor XIa), S-2238 (thrombin), and plasma prekallikrein activator were purchased from Pharmacia (Franklin, $\mathrm{OH}$ ). Microplates (tissue culture treated no. 3072 or 3075) were obtained from Falcon Plastics (Mt. Laurel, NJ). Human serum albumin and rat albumin were both purchased from Sigma Chemical Co. (St. Louis, MO).

\section{Cell Wall Preparation}

PG-APS polymers with a molecular weight ranging from $5 \times 10^{6}$ to $5 \times 10^{7}$ daltons were prepared from the cell walls of group A, type 3, strain D58 streptococci (Streptococcus pyogenes) as described previously. ${ }^{4,29}$ Immediately before injection, the cell walls were diluted to appropriate concentrations in phosphate-buffered saline and sonicated for 30 seconds in a water bath to disperse aggregates. Aseptic techniques were used, and sterility was confirmed by culturing $0.1 \mathrm{~mL}$ on sheep blood agar. Rhamnose was assayed by the method of Dische and Shettles ${ }^{30}$ and used to calculate final PG-APS polymer concentrations.

\section{Experimental Protocol}

A total of 135 inbred specific pathogen-free female rats, weighing 135-155 g (6-7 weeks of age), were used for 
the in vivo studies. Seventy Lewis rats were obtained from Charles River Breeding Laboratories Inc. (Raleigh, NC), and 65 Buffalo rats were purchased from Simonson Laboratories (Gilroy, CA). Rats were housed together in a specific pathogen-free room for 5-10 days before surgery was performed and for the duration of these studies. Rats were maintained in isolation, fed standard rat chow and water, and periodically tested for serological and culture evidence of recognized rodent pathogens. Plasma was obtained from 5 separate Lewis and 5 Buffalo rats for the in vitro studies. Rats were maintained under specific pathogen-free conditions and allowed free access to food and water during the course of the experiments. Intestines were exposed by laparotomy using aseptic technique after induction of anesthesia by intramuscular injection of $1.3 \mathrm{~mL} /$ $\mathrm{kg}$ body wt Innovar (Pitman-Moore Co., Washington Crossing, NJ). Lewis or Buffalo rats were injected intramurally (subserosally) with either PG-APS ( $45 \mu \mathrm{g}$ dry wt and $15 \mu \mathrm{g}$ rhamnose/g body wt) or human serum albumin $(45 \mu \mathrm{g} / \mathrm{g})$ as described previously. ${ }^{4}$ At each site, $0.05 \mathrm{~mL}$ (one ninth of total dose) was injected 2 and $4 \mathrm{~cm}$ proximal to the ileocecal valve at the junction of the mesentery and ileum, into two distal ileal Peyer's patches, and into the lymphoid aggregate at the cecal tip. Two midcecal sites were injected subserosally with $0.1 \mathrm{~mL}$ each of PG-APS or human serum albumin. The abdominal cavity was closed in two layers with absorbable (peritoneum and muscle layers) and silk (skin) sutures. Four to six rats from each group were killed by $\mathrm{CO}_{2}$ narcosis at $1,5,8$, 14 , and 24 days and $6,8,12$ and 16 weeks postinjection. A group of 10 normal Lewis rats served as assay controls as well as a source of pooled normal rat plasma.

\section{Assessment of Inflammation and Collection of Specimens}

Rats were weighed twice weekly for 2 weeks and then weekly for the duration of the experiment. Ankle joints were scored for swelling and erythema on a $0-4$ scale $^{11}$ when the rats were weighed. At necropsy, performed by blinded observers, intestinal and systemic inflammation was determined by gross examination, white blood cell counts, and hematocrits on cardiac blood, myeloperoxidase, analysis of intestinal specimens, and histological evaluation. A gross gut score was calculated using the sum of $0-4$ determinations of intestinal wall thickening, adhesions, mesenteric contraction, and serosal nodules as described previously. ${ }^{3,4}$ Hepatic granulomas were quantitated on a $0-4^{+}$scale. Samples from each intestinal injection site were collected on dry ice and stored at $-70^{\circ} \mathrm{C}$ for myeloperoxidase assay and fixed in $10 \%$ buffered formalin for histological processing. Blood samples were aspirated from the right ventricle by an 18-gauge needle into a syringe containing 0.1 $\mathrm{mol} / \mathrm{L}$ sodium citrate (final ratio of citrate to blood was 1:9) for biochemical measurements of the kallikrein-kinin system in rats killed 5, 24, and 42 days after PG-APS or human serum albumin injection. Plasma was isolated by double centrifugation of citrated blood in polypropylene tubes at room tempera- ture $e^{20}$ and then was stored at $-70^{\circ} \mathrm{C}$. A separate sample of cardiac blood was taken for hematologic measurements.

\section{Histological Inflammatory Score}

Blinded histological assessment of acute and chronic inflammation was performed using a modification of our previously validated scoring system. ${ }^{3,4}$ Values of $0-4$ (4 being the most severe) were assigned using our previously described criteria $^{3}$ for acute and chronic inflammatory cell infiltrations at each site. Acute and chronic scores were assigned for each of the four injection sites (Peyer's patch, distal ileum, cecal tip, and midcecum), and the results were summed so that the maximal score was 32. The presence of mucosal ulceration, crypt abscesses, and granulomas was noted.

\section{Myeloperoxidase Assay}

Intestinal myeloperoxidase activity was determined using a minor modification of the method of Grisham et al. ${ }^{31}$ Briefly, intestinal tissue was homogenized in $20 \mathrm{mmol} / \mathrm{L}$ phosphate buffer ( $\mathrm{pH} 7.4$ ) and centrifuged at $6000 \mathrm{~g}$ for 20 minutes at $4^{\circ} \mathrm{C}$. The pellet was homogenized and sonicated with an equivalent volume of $50 \mathrm{mmol} / \mathrm{L}$ potassium phosphate buffer $(\mathrm{pH} 6.0)$ containing $0.5 \%$ (wt/vol) hexadecyltrimethylammonium hydroxide. Myeloperoxidase activity was determined by measuring the $\mathrm{H}_{2} \mathrm{O}_{2}$-dependent oxidation of 3,3'5,5'-tetramethylbenzidine and normalized for tissue weight.

\section{Assays of Coagulation and Contact Activation}

Antithrombin III was measured by a functional amidolytic microplate assay using the Coatest Antithrombin Kit (Helena Laboratories, Beaumont, TX). ${ }^{32}$ Prekallikrein levels were determined by a functional amidolytic assay described previously. ${ }^{33}$ Factor XI functional activity was determined by a method developed in this laboratory. ${ }^{34}$ High-molecular-weight kininogen coagulant activity was determined by a slight modification of the method of Proctor and Rapaport ${ }^{35}$ using human total kininogen deficient plasma. ${ }^{36}$

\section{Determination of T-Kininogen and $\alpha_{1}$-Inhibitor 3 in Rat Plasma}

T-kininogen and $\alpha_{1}$-inhibitor 3 were measured by sandwich enzyme-linked immunosorbent assays. ${ }^{37}$ T-kininogen was purified as described previously. ${ }^{38}$ Purified $\alpha_{1}$-inhibitor 3 was purified according to the method of Moreau et al. ${ }^{39}$ Polyclonal antibodies were developed against T-kininogen and $\alpha_{1}$-inhibitor 3. ${ }^{37}$ The polyclonal immunoglobulin Gs were isolated from the immune sera by the use of affinity chromatography on protein $G$, according to the recommendations of the manufacturer (Pharmacia, Uppsala, Sweden). The purity of this material was monitored using absorbance ratio $278: 252 \mathrm{~nm}$ $(>1.5)$ and its recovery at $278 \mathrm{~nm}$. The purified proteins (immunoglobulins) were used for the coating of plates and for labeling. Fifteen milligrams of these purified immunoglobu- 
lins was labeled with horseradish peroxidase (Boehringer Mannheim, Indianapolis, IN) using the method described by Tijssen. ${ }^{40}$ Nunc immunoplates (Nunc, Roskilde, Denmark) were coated for 18 hours at $4^{\circ} \mathrm{C}$ with $100 \mu \mathrm{L}$ of affinity purified immunoglobulin $\mathrm{G}(5 \mu \mathrm{g} / \mathrm{mL})$ diluted in $100 \mathrm{mmol} / \mathrm{L}$ sodium carbonate buffer, $\mathrm{pH}$ 9.2. The plates were then washed five times in incubation buffer (containing $50 \mathrm{mmol} / \mathrm{L}$ Tris $\mathrm{HCl}$; $100 \mathrm{mmol} / \mathrm{L} \mathrm{NaCl}, \mathrm{pH} \mathrm{7.4}$; and $0.05 \%$ Tween 20) and saturated for 1 hour at $37^{\circ} \mathrm{C}$ with $200 \mu \mathrm{L}$ of incubation buffer. The plates were washed and incubated for 3 hours at $37^{\circ} \mathrm{C}$ with $100 \mu \mathrm{L}$ of the biological samples or the standard diluted in the incubation buffer. The plates were then washed again and incubated for 3 hours at $37^{\circ} \mathrm{C}$ with $100 \mu \mathrm{L}$ of labeled immunoglobulin Gs diluted 1:4000 in the incubation buffer. After further washing, the presence of immune complexes was detected by the addition of $100 \mu \mathrm{L}$ of substrate solution (100 $\mathrm{mmol} / \mathrm{L}$ orthophenylene diamine; Sigma Chemical Co.) and $0.01 \%$ urea hydrogen peroxide (from Sigma Chemical Co.), in citrate buffer $(0.08 \mathrm{~mol} / \mathrm{L}, \mathrm{pH} 5)$. After 30 minutes at $25^{\circ} \mathrm{C}$, absorbances were measured at $450 \mathrm{~nm}$ using $650 \mathrm{~nm}$ as the reference wavelength.

\section{In Vitro Activation of Kallikrein and Kinin}

Rabbit antiserum against rat high-molecular-weight kininogen (obtained from Dr. A. Adam) was purified using a protein A purification column. ${ }^{41}$ The purified immunoglobulins were labeled with biotin according to the method of Hock et al. ${ }^{42}$ In brief, the protein was dialyzed against $0.1 \mathrm{~mol} / \mathrm{L}$ $\mathrm{NaHCO}_{3}, \mathrm{pH} 8.0$, and diluted to $1 \mathrm{mg} / \mathrm{mL}$ by the addition of the same buffer. One hundred liters of $1 \mathrm{mg} / \mathrm{mL}$ of biotine-aminocapronyl- $N$-hydroxysuccinimide in dimethyl sulfoxide was added to $1 \mathrm{~mL}$ of the protein solution (molar ratio of protein/biotin, 1:18). After incubation for 4 hours at $23^{\circ} \mathrm{C}$, the mixture was dialyzed against phosphate-buffered saline. The specificity and sensitivity of antibody reactivity to highmolecular-weight kininogen were analyzed by Western blot. The antibodies were found to cross-react with rat serum albumin and to cross-react weakly with T-kininogen.

The contact system of citrated pooled Lewis or Buffalo rat plasma was activated by incubation with $1 \mathrm{mg} / \mathrm{mL}$ kaolin (Fisher Laboratories) in phosphate-buffered saline in proportion (9:1, vol/vol) or purified human plasma kallikrein $(0.2 \mu \mathrm{mol} /$ L) prepared as described previously ${ }^{43}$ at $23^{\circ} \mathrm{C}$. At 3-, 6-, and 15-minute intervals, aliquots of the incubation mixture were removed for Western blot analysis of high-molecular-weight kininogen and kallikrein assay.

Western blot of high-molecular-weight kininogen cleavage using anti-high-molecular-weight kininogen antibodies. Two microliters of either pooled Lewis and Buffalo rat plasma inactivated ( 0 time point) or activated with kaolin or human plasma kallikrein at indicated time intervals was transferred to sample buffer containing sodium dodecyl sulfate. Plasma from a brown Norway rat strain (BN/Mai Pfd) deficient in both high-molecular-weight kininogen and low-molecularweight kininogen was used as a control. Electrophoresis was performed according to the method of Laemmli ${ }^{44}$ on $4 \%-20 \%$ polyacrylamide gradient gels (Bio-Rad Laboratories, Richmond, CA) using a Hoefer SE apparatus. The plasma proteins were then electrotransferred to a polyvinyl difluoride membrane using a Trans-blot SD semidry transfer cell (Bio-Rad Laboratories, Hercules, CA) at a constant current of $240 \mathrm{~mA}$ for 45 minutes. The membrane was blocked overnight with $10 \%$ nonfat Irish cream at $4{ }^{\circ} \mathrm{C}$ on a rotary shaker and then incubated with purified, biotin-labeled anti-high-molecularweight kininogen antibodies in phosphate-buffered salineNonidet P40 (Boehringer Mannheim) for 2 hours. After extensive washing, the polyvinyl difluoride membrane was incubated with avidin-alkaline phosphatase (Sigma Chemical Co.) in phosphate-buffered saline-Nonidet P40 for 1 hour. Finally, 5-bromo-4-chloro-3 indoyl phosphate/nitroblue tetrazolium chloride phosphate substrate (Kirkegaard/Perry Laboratories) was added to develop the membrane.

Amidolytic assay for kallikrein generation. Fifty microliters of pooled Lewis and Buffalo rat plasma either inactivated (baseline, 0 point) or activated by kaolin (at 1, 3, 6, and 15 minutes) was transferred to a microplate containing $50 \mu \mathrm{L}$ of $2 \mathrm{mmol} / \mathrm{L} \mathrm{S}$-2302. After a 10-minute incubation, the substrate hydrolysis was stopped by the addition of an equal volume of $50 \%$ acetic acid. The absorption was read at $405 \mathrm{~nm}$ in a microplate reader and converted to micromoles of substrate hydrolyzed per minute by reference to a $p$-nitroaniline standard as described previously (AB Kabi Diagnostica, Stockholm, Sweden). ${ }^{33}$

\section{Statistical Analysis}

A group of animals $(n=10)$ that received neither saline nor PG-APS was used to normalize the contact system data from the control groups (human serum albumin injected) or the PG-APS-treated groups. Differences between control groups at different intervals for biochemical parameters were evaluated by the two-way analysis of variance method of Newman-Keuls ${ }^{45}$ to validate the data. The unpaired two-tailed Student's $t$ test was then used to evaluate differences between control and treated groups at each interval. $P$ values of $\leq 0.05$ were considered significant. Correlations between high-molecular-weight kininogen or plasma prekallikrein activity from the PG-APS-treated group with their corresponding clinical gross gut, joint, and hepatic granuloma scores were evaluated by linear regression analysis.

\section{Results}

\section{Intestinal Inflammation}

Both Lewis and Buffalo rats developed acute inflammation at the injection site manifested by edema, hemorrhage, thickening of the bowel wall and mesentery, and adhesions. Acute intestinal inflammation peaked at 1 day after PG-APS injection and slowly diminished over 8 days, as indicated by blinded gross gut scores (Figure 

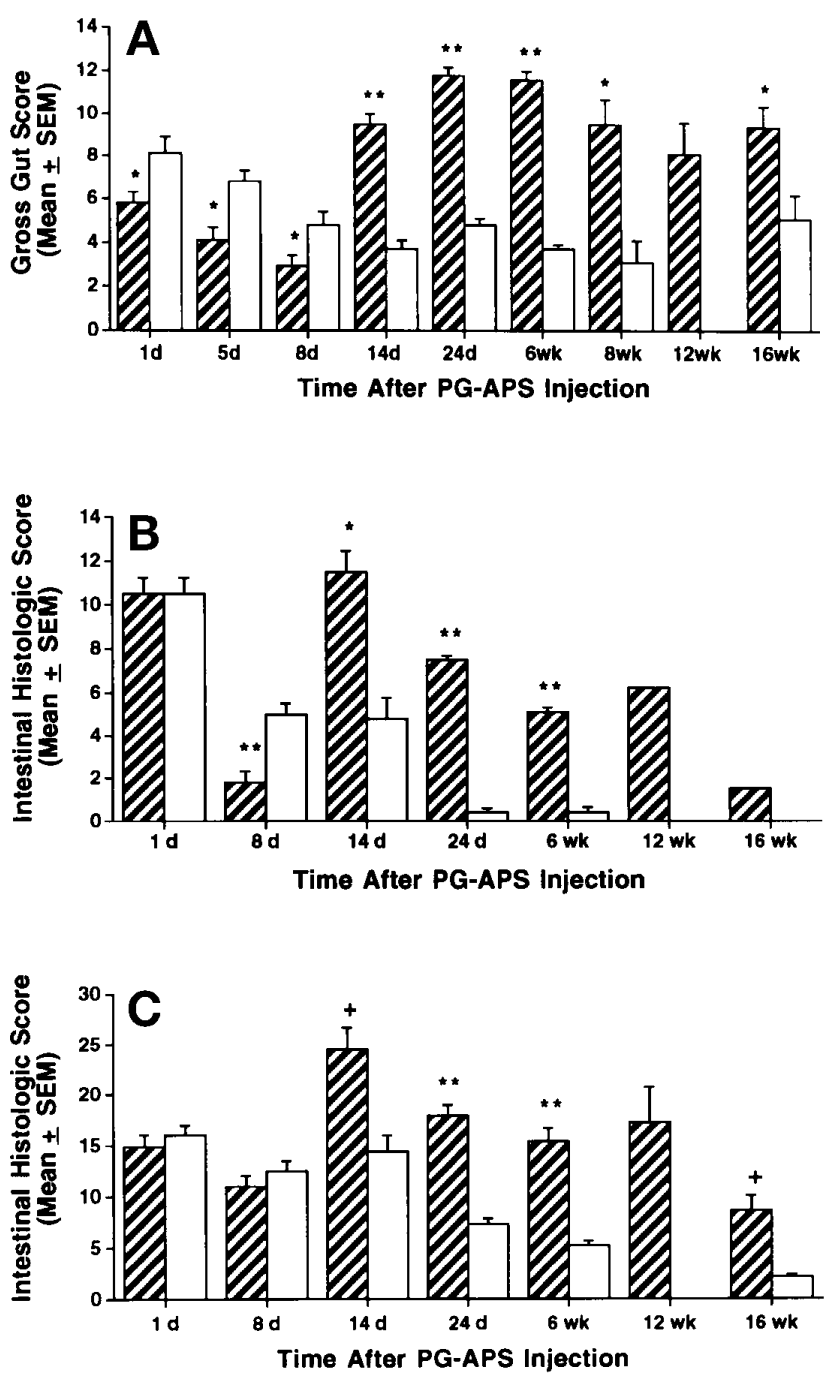

Figure 1. Clinical and histological evidence of intestinal inflammation in Lewis $(\mathbb{Z})$ and Buffalo $(\square)$ rats at intervals after a single subserosal injection with PG-APS ( $45 \mu \mathrm{g} / \mathrm{g}$ body wt). ( $A$ ) Gross inflammation. (B) Acute histological inflammation. $(C)$ Total histological inflammation. (A) Blinded gross gut scores were calculated as the sum of serosal nodules, adhesions, bowel wall thickening, and contracted mesentery as described in Materials and Methods. ( $B$ and $C$ ) Blinded histological intestinal inflammatory scores after subserosal PG-APS injection in Lewis and Buffalo rats. (B) Acute-phase histological inflammatory score is based on the degree of infiltration with neutrophils, tissue necrosis, and edema. $(C)$ The total histological inflammatory score was calculated by adding the acute-phase and chronic-phase components of each injection site. Values are expressed as mean \pm SEM. ${ }^{*} P \leq 0.02,{ }^{*} * P<0.001,{ }^{\dagger} P=0.006$ vs. Buffalo rats.

$1 A)$. During the acute phase, Buffalo rats had consistently higher gross scores than Lewis rats. Human serum albumin-injected rats had scores ranging from 0 to 2 , with a mean score of $0.4 \pm 0.3$ for Lewis rats and $0.5 \pm$ 0.4 for Buffalo rats. Beginning around 14 days after PG-APS injection, Lewis rats spontaneously developed chronic enterocolitis with dense adhesions, thickening of intestinal wall, serosal nodules, and enlarged mesenteric lymph nodes. Chronic inflammation was diffuse in the cecum and distal ileal mesentery and clearly occurred between injection sites. Chronic enterocolitis persisted for at least 16 weeks in Lewis rats. In striking contrast, gross inflammatory scores in Buffalo rats diminished by 2 weeks and did not relapse over the 16-week period of observation. Buffalo rats did not develop serosal granulomas, bowel wall thickening, or dense adhesions, although residual adhesions and mesenteric contractions remained for the duration of the study as a consequence of the acute inflammatory response.

Histological assessment of inflammation confirmed the gross observations. Both Lewis and Buffalo rats showed acute focal inflammation at the site of injection, with neutrophils and macrophages being the most predominant infiltrating cells. Focal necrosis was frequently observed in the submucosa and mesentery; mucosal ulceration was quite rare. Beginning 14 days after PG-APS injection, Lewis rats developed chronic, granulomatous enterocolitis with extensive fibrosis. Inflammation was most marked in the submucosa, serosa, and mesentery, but granulomas in the lamina propria, crypt abscesses ( $50 \%$ of rats), and occasional fissure-like mucosal ulcers indicated active mucosal inflammation. Mononuclear cells predominated but focal accumulations of neutrophils and crypt abscesses were present at all time points (Table 1). In contrast, Buffalo rats developed aggressive acute inflammation but had very limited evidence of chronic granulomatous enterocolitis. Blinded histological intestinal inflammatory scores showed different kinetics of inflammation in the inbred rat strains (Figure $1 B$ and $C)$. Buffalo rats had a more protracted acute phase (14 days) of enterocolitis that resolved by 24 days. Total inflammatory scores in Buffalo rats continued to resolve over a 16-week period. In contrast, Lewis rats had acute inflammation that diminished by 8 days but spontaneously reactivated 14 days after a single PG-APS injection and remained active for at least 16 weeks. By 16 weeks, $40 \%$ of Lewis rats had histological evidence of acute inflammation, as opposed to $100 \%$ at 6 and 12 weeks. Histological scores for human serum albumin-injected controls ranged from $3.6 \pm 0.2$ at 4 days to $0.6 \pm 0.2$ by 6 weeks after injection; no difference in histological scores was noted between Lewis and Buffalo control rats.

Cecal myeloperoxidase values provided biochemical confirmation of biphasic, spontaneously reactivating inflammation in Lewis rats and self-limited injury in Buffalo rats (Figure 2). Furthermore, tissue myeloperoxidase concentrations showed the more protracted course of acute inflammation in Buffalo rats, which showed peak 
Table 1. Incidence of Relapsing Enterocolitis and Extraintestinal Inflammation in Inbred Rats 14 Days or Longer After PG-APS Injection

\begin{tabular}{lcccrrr} 
& Intestinal granulomas & Acute gut inflammation & Hepatic granulomas & Arthritis & Anemia & Leukocytosis \\
\hline Buffalo rats & $11^{a}$ & $26^{b}$ & 4 & 0 & 11 & 13 \\
Lewis rats & 91 & 87 & 73 & 84 & 84 & 100 \\
\hline
\end{tabular}

NOTE. Acute gut inflammation is defined by a histological score of acute inflammation of $>2$.

aPercent of rats injected subserosally with PG-APS.

${ }^{b}$ All slides showing acute inflammation were from rats killed 14 days after PG-APS injection.

biochemical values at 14 days after PG-APS injection compared with peak acute values on day 5 in Lewis rats. By 6 weeks, however, myeloperoxidase values in Lewis rats were significantly higher than in Buffalo rats, which had returned to control values. Control cecal myeloperoxidase concentrations were $0.41 \pm 0.09$ in Lewis rats injected with human serum albumin and $0.71 \pm 0.24$ in Buffalo rats.

\section{Systemic Inflammation}

A marked disparity existed in the incidence of extraintestinal manifestations in Lewis and Buffalo rats (Figure 3). Arthritis and hepatic granulomas occurred in $73 \%$ of Lewis rats examined 14 days or more after PG-APS injection; however, only $4 \%$ of Buffalo rats developed hepatic granulomas, and arthritis was not evident in Buffalo rats (Table 1). Arthritis was predictably observed in the rear ankle joints of Lewis rats and only

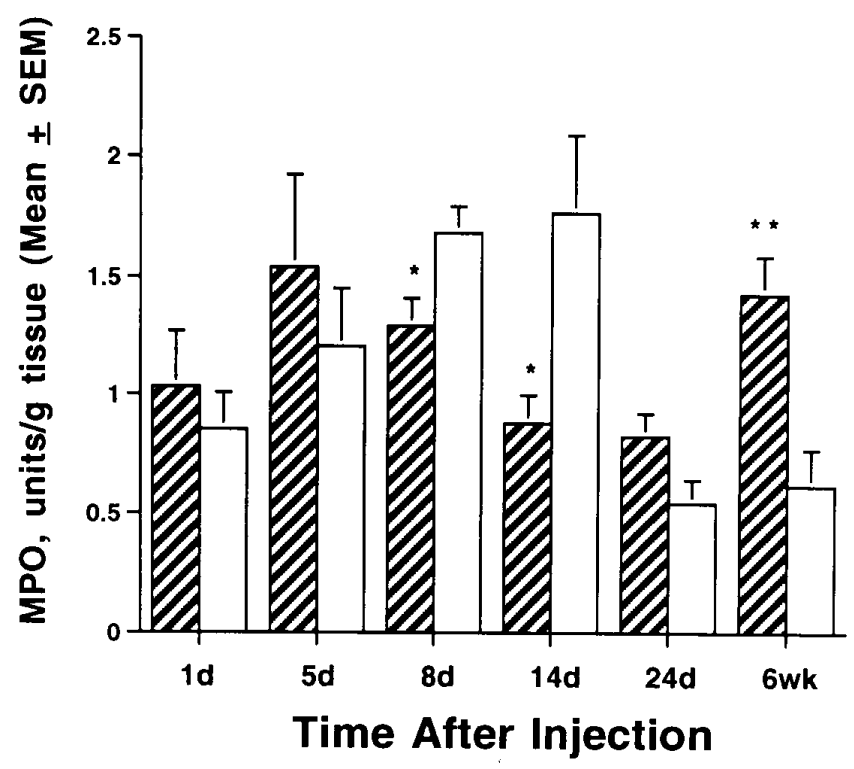

Figure 2. Cecal myeloperoxidase (MPO) concentrations in Lewis (שיA) and Buffalo $(\square)$ rats at intervals after subserosal injection of PG-APS. Myeloperoxidase values were normalized by tissue sample weights (in grams). $* P \leq 0.05, * * P \leq 0.01$ vs. Buffalo rats. rarely in the forepaws. Histological examination showed erosion of the articular cartilage with pannus formation, exudate in the synovial space, hyperplasia of the synovial lining, and granulomatous inflammation in the periarticular tissue. Hepatic granulomas were macroscopically evident and consisted of well-defined aggregates of mononuclear cells with concentric fibrosis and occasional central necrosis. Granulomas were frequently located near portal tracts but also occurred in the parenchyma. Hepatic granulomas were not observed before 14 days after PG-APS injection in Lewis rats and became more fibrotic with fewer inflammatory cells by 16 weeks. Splenic enlargement and necrosis was observed in both rat strains beginning around 8 days after gut injection of PG-APS.

Like intestinal inflammation, anemia and leukocytosis persisted for the duration of the experiment in Lewis rats and were self-limited but more pronounced in the acute phase of inflammation in Buffalo rats (Figure 4). It should be noted that control hematocrit values were greater in Lewis rats than Buffalo rats injected with human serum albumin (Figure $4 A$ ), but control white blood cell count concentrations were similar in the two
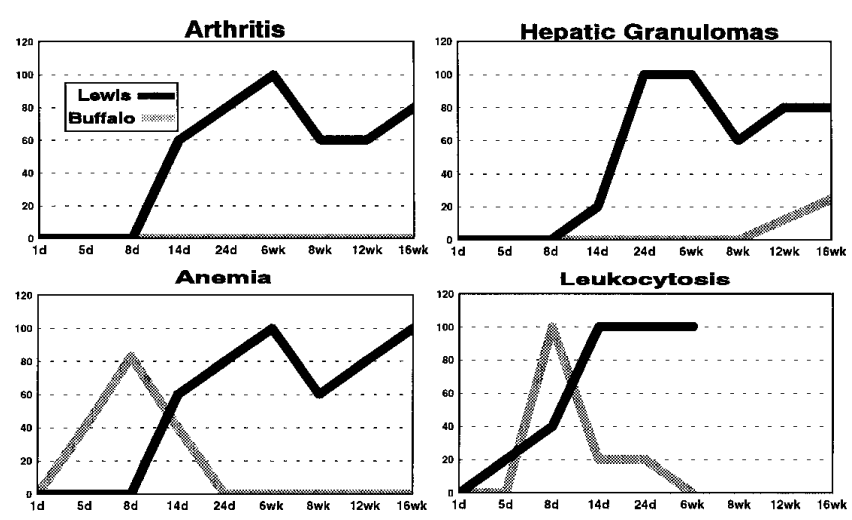

Figure 3. Incidence of systemic inflammation in inbred rats at intervals after subserosal injection of PG-APS. The percentage of rats with systemic inflammation relative to the total number of rats injected with PG-APS at each time point is shown. 

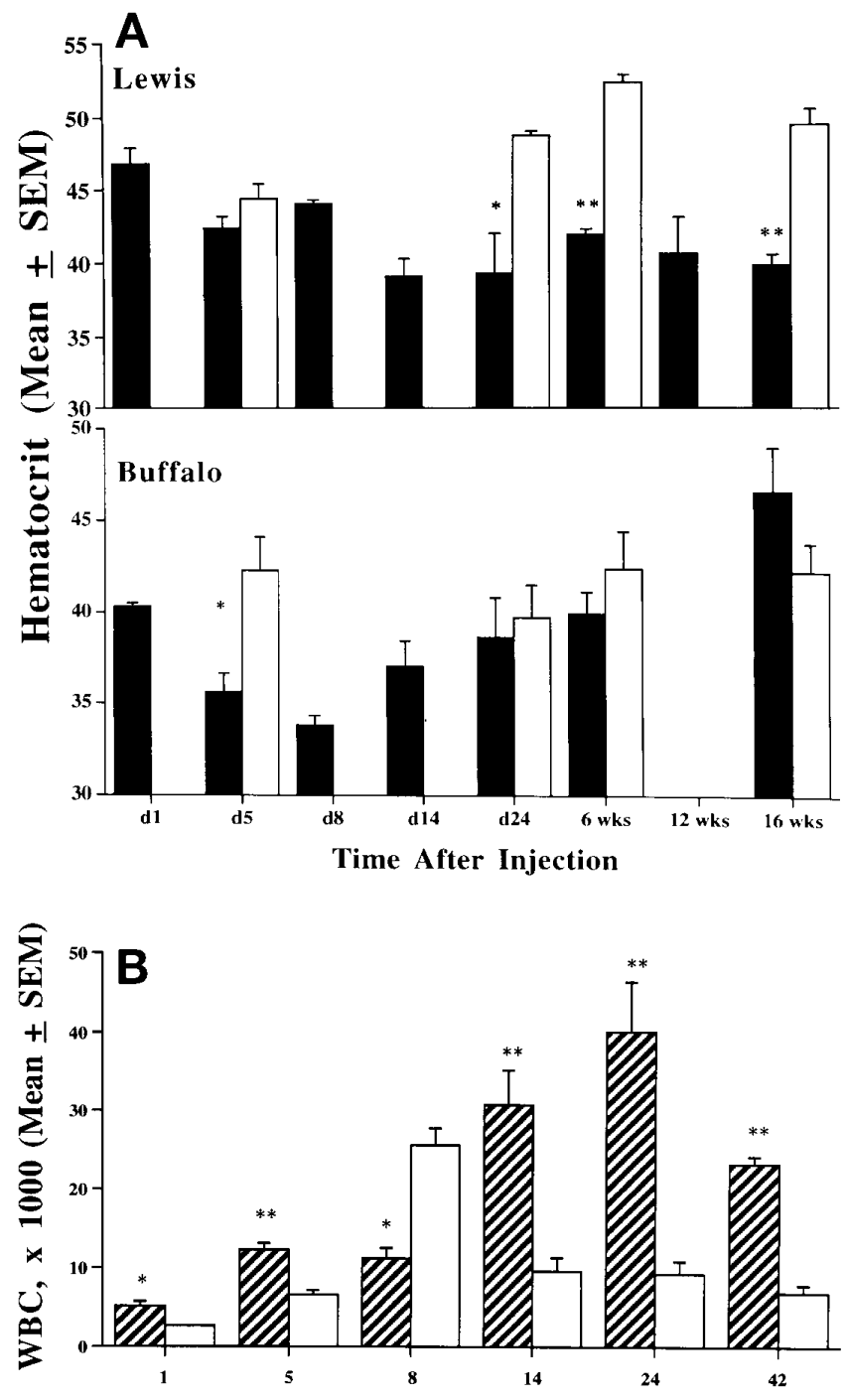

Days After Injection

Figure 4. Hematologic parameters in Lewis and Buffalo rats after subserosal PG-APS injection ( $\boldsymbol{\square}$ ) or human serum albumin injection $(\square)$. (A) Hematocrit values on cardiac blood were transiently decreased in Buffalo rats after PG-APS injection, but chronic anemia persisted for the duration of the experiment only in Lewis rats. $* P<$ $0.05, * * P<0.001$ vs. human serum albumin injected. $(B)$ White blood cell counts (WBC) were persistently elevated only in Lewis rats. $* P<0.05, * * P<0.001$ vs. human serum albumin injected. Lewis rats $(\mathscr{Z})$ compared with Buffalo rats $(\square)$ during the chronic phase of PG-APS-induced inflammation. ${ }^{*} P=0.01, * * P<0.001$ vs. Buffalo rats.

inbred strains $\left(7.6 \times 10^{3} / \mu \mathrm{L}\right.$ Lewis rats and $7.9 \times 10^{3} /$ $\mu \mathrm{L}$ Buffalo rats).

\section{Spontaneous Reactivation of Enterocolitis in Lewis Rats}

The biphasic course of the gross and histological gut inflammatory scores and myeloperoxidase values
(Figures 1 and 2) clearly show that Lewis rats had spontaneously reactivating intestinal inflammation. The active nature of chronic enterocolitis in Lewis rats is further documented by histological detection of intestinal neutrophils and granulomas in the great majority of Lewis rats (Table 1). The first indications of reactivating inflammation around 14 days after PG-APS injection were a 5-10 g weight loss, lethargy, bloody conjuctiva and nostrils, and scruffy fur. These findings preceded the onset of arthritis by $1-3$ days. Arthritis or hepatic granulomas were never found in the absence of intestinal granulomas, although gut lesions were observed occasionally without joint or hepatic lesions, suggesting that gut lesions predated the onset of arthritis and hepatobiliary disease. By all criteria, no active inflammation was evident in Buffalo rats 24 days or more after PG-APS injection.

\section{Acute-Phase Proteins}

Biochemical assays of plasma acute-phase reactants, contact system proteins, and indicators of hepatic protein synthesis were measured at representative time points during the acute ( 5 days) and chronic (24 and 42 days) phases of inflammation. T-kininogen represents a major acute-phase protein in the rat. T-kininogen levels increased in the PG-APS-treated Lewis rats from $0.97 \pm 0.41 \mathrm{mg} / \mathrm{mL}$ to $2.3 \pm 0.53 \mathrm{mg} / \mathrm{mL}$ by day 5 and peaked at $6.8 \pm 3.3 \mathrm{mg} / \mathrm{mL}$ on day 24 (Figure $5 A$ ). By day 42, T-kininogen levels decreased to $3.9 \pm 1.4$ $\mathrm{mg} / \mathrm{mL}$ but remained significantly higher than control levels. No significant changes were observed in PG-APStreated Buffalo rats or human serum albumin-injected controls.

$\alpha_{1}$-Inhibitor 3 represents a negative acute-phase protein in the rat. $\alpha_{1}$-Inhibitor 3 baseline levels were found to be consistently lower in the human serum albumintreated Buffalo rats than in the control Lewis rats (Figure $5 B$ ). The $\alpha_{1}$-inhibitor 3 concentrations in the PG-APSinjected Lewis rats decreased significantly during chronic inflammation (days 24 and 42) when compared with their respective human serum albumin-treated controls. In contrast, $\alpha_{1}$-inhibitor 3 levels in Buffalo rats injected with PG-APS showed no difference from control values at any time point, despite the presence of active, acute inflammation at day 5 .

\section{Biochemical Assays of Contact System Proteins}

Prekallikrein levels were significantly lower in PG-APS-treated Lewis rats compared with controls or Buffalo rats during both acute and chronic phases of 
inflammation (Figure 6A). By day 5 , the concentrations decreased from $82.7 \% \pm 2.5 \%$ (human serum albumininjected controls) to $67.1 \% \pm 1.2 \%(P<0.01)$ and remained lower than control levels through day 42 $(68.9 \% \pm 2.4 \%)$. No changes in prekallikrein concentrations were evident in Buffalo rats injected with PG-APS at any time point, including during active inflammation at 5 days. Factor XI levels were not affected in either strain (data not shown).

We observed a biphasic decrease in the functional levels of high-molecular-weight kininogen in Lewis rats injected with PG-APS (Figure 6B). High-molecular-weight kininogen levels were significantly decreased in PG-APS-treated Lewis rats on day $5(63.6 \% \pm 6.6 \%$ vs. $101.0 \% \pm 12.4 \%$ from its respective control group) and day $42(58.8 \% \pm$ $6.4 \%$ vs. $104.4 \% \pm 11.4 \%$ from its respective control group) but not at the 24-day time period. These results are in direct contrast to stable plasma high-molecular-weight kininogen concentrations in Buffalo rats injected with PGAPS at all time points, even during active gross and histological inflammation at day 5 .

\section{Antithrombin III}

There were no significant differences between functional levels of antithrombin III in any of the ana-
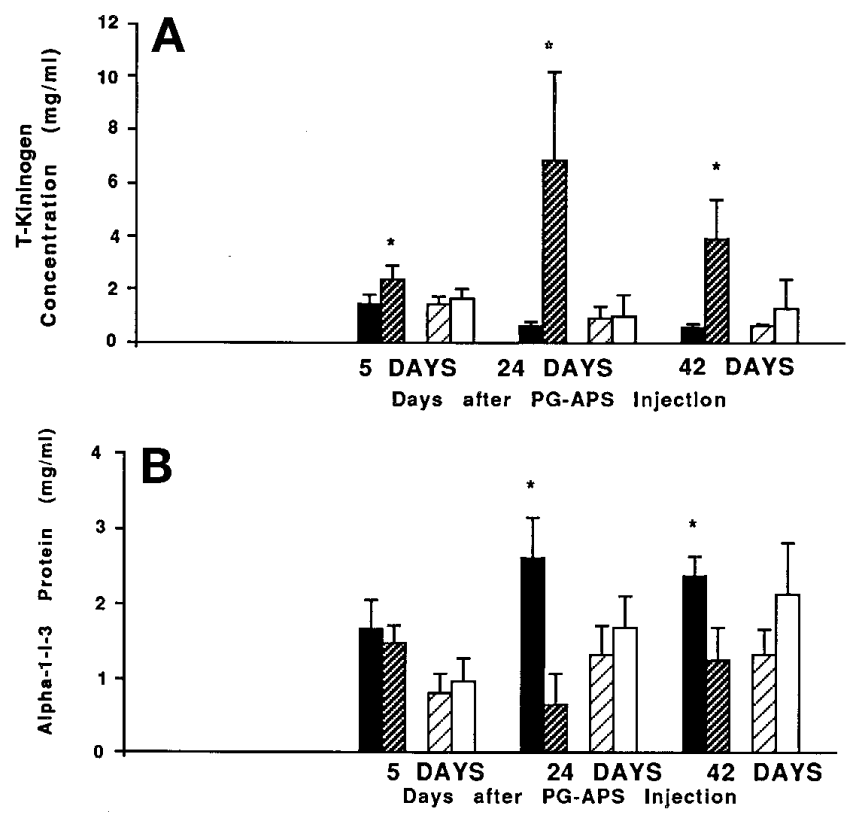

Figure 5. Biochemical assays of plasma acute-phase reactants. (A) Tkininogen levels were elevated in Lewis rats injected with PG-APS during acute and chronic phases of inflammation but unchanged in Buffalo rats. $* P<0.05$. (B) $\alpha_{1}$-inhibitor 3 protein, a negative acute-phase reactant, was decreased in Lewis rats but not in Buffalo rats injected with PGAPS relative to human serum albumin-injected rats. $* P<0.01$. $\mathbf{\square}$, Lewis rats + human serum albumin; $\mathbb{Z}$, Lewis rats + PG-APS; $\triangle$, Buffalo rats + human serum albumin; $\square$, Buffalo rats + PG-APS. lyzed groups in this study (data not shown). Because plasma antithrombin III may be markedly depleted by disseminated intravascular coagulation or decreased because of lack of synthesis in severe liver disease, it is likely that neither of these conditions account for the observed changes in contact system proteins.

\section{Correlation of Clinical and Biochemical Results}

Biochemical measures of contact system activitation were correlated with clinical parameters by linear regression analysis. During the chronic phase, gross gut scores, arthritis, and hepatic granulomas closely correlated with plasma prekallikrein and high-molecularweight kininogen values (individual correlations ranging from $r=-0.74\{P=0.01\}$ to $r=-0.94\{P<0.001\})$ 42 days after PG-APS injection. At this time point, plasma prekallikrein and high-molecular-weight kininogen values were significantly correlated with each other $(r=0.71 ; P=0.016)$. Plasma prekallikrein values correlated with clinical scores 24 days after PG-APS injection, but high-molecular-weight kininogen values did not. No such correlation was observed during the acute phase of
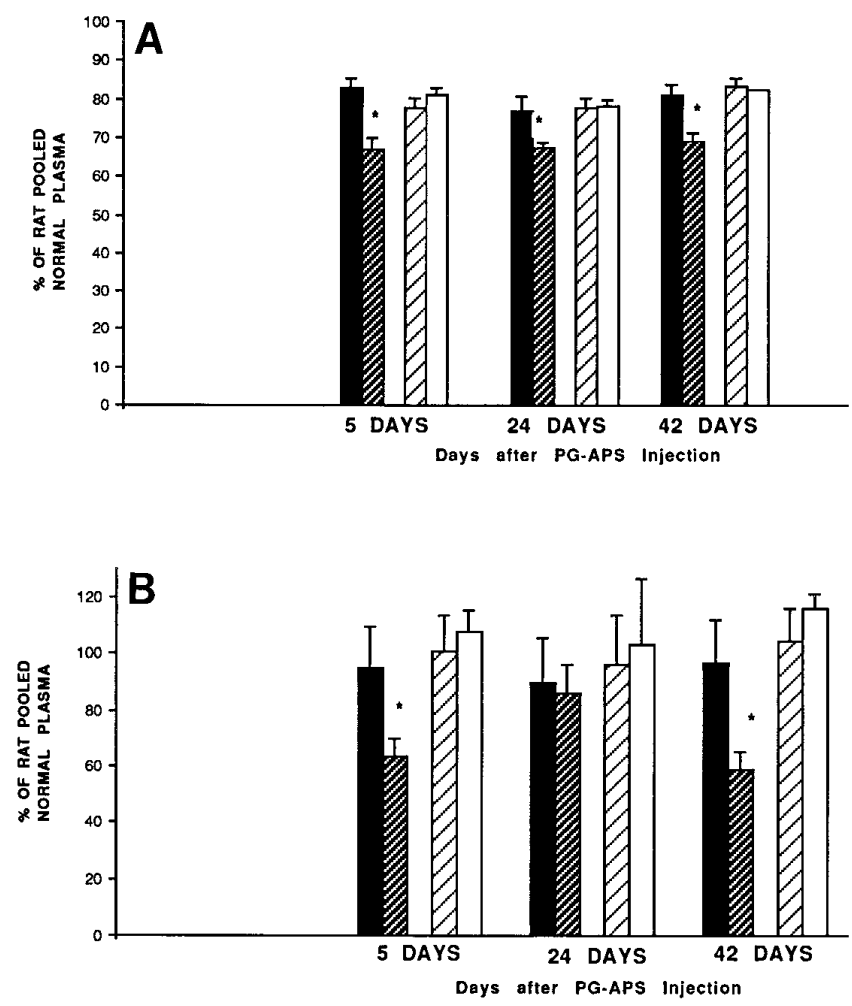

Figure 6. Functional assays of contact system proteins. (A) Prekallikrein and $(B)$ high-molecular-weight kininogen levels are expressed as a percentage of pooled normal rat plasma values. $* P<0.01$. $\mathbf{\square}$, Lewis rats + human serum albumin; $\mathbb{Z}$, Lewis rats + PG-APS; $\mathbb{Z}$, Buffalo rats + human serum albumin; $\square$, Buffalo rats + PG-APS. 
PG-APS-induced inflammation because of the lack of prekallikrein and high-molecular-weight kininogen activation in Buffalo rats with acute enterocolitis.

\section{In Vitro Activation of Kallikrein and Kininogen by Kaolin}

To determine whether the observed lack of plasma prekallikrein and high-molecular-weight kininogen consumption in Buffalo rats was caused by a failure of activation of the contact system or a more rapid inhibition of this cascade, we activated the contact system in vitro with kaolin.

Analysis of high-molecular-weight kininogen cleavage by Western blotting. As shown in Figure $7 \mathrm{~A}$ under reducing conditions, single-chain high-molecularweight kininogen (molecular weight, 120 kilodaltons) was visualized in both Lewis and Buffalo plasma. In contrast, the kininogen-deficient brown Norway plasma sample did not show a band corresponding to high-molecular-weight kininogen. Although the volume of plasma is identical, the Buffalo rat seems to have a higher concentration of high-molecular-weight kininogen than the Lewis rat. In Lewis rat plasma, the high-molecularweight kininogen band is progressively decreased after exposure to kaolin. In Buffalo rat plasma, little change in intensity is noted. Laser densitometric scanning (Table 2) showed that high-molecular-weight kininogen was consumed more rapidly and more completely in plasma from Lewis rats than Buffalo rats. Similar results were found in three separate experiments. The bands indicating the high-molecular-weight kininogen cleavage products, high chain (molecular weight, 62 kilodaltons) and light chain (molecular weight, 41 kilodaltons), were observed in both Lewis and Buffalo lanes but not in brown Norway plasma. The lower immunologic reactivity of the heavy and light chains do not allow a meaningful comparison. Thus, this assay indicates that Buffalo rat plasma high-molecular-weight kininogen is cleaved more slowly after exposure to an anionic surface (kaolin) compared with Lewis rat plasma high-molecular-weight kininogen.

Lewis and Buffalo rat plasma samples were assayed for kallikrein activity, as measured by hydrolysis of a chromogenic substrate S-2302, after kaolin exposure (Figure $7 B$ ). In both Lewis and Buffalo plasma, the kallikrein activity 1 minute after activation was markedly increased over baseline to $9.8 \pm 0.8$ and $9.4 \pm 1.5 \mu \mathrm{mol} /$ min, respectively, and remained increased in samples evaluated after 3 minutes of activation. The degree of kallikrein generation was not significantly different in Lewis and Buffalo plasma at any time points. The kalli-
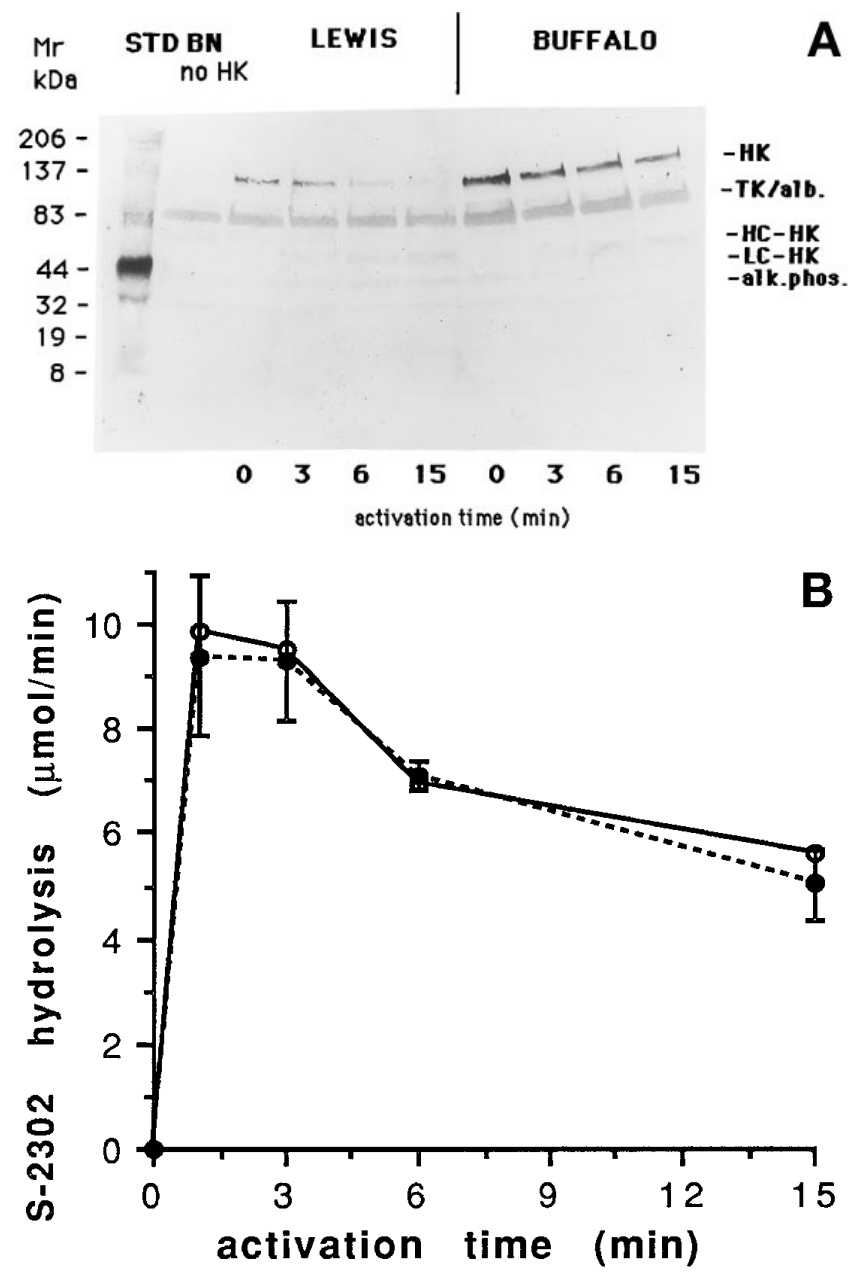

Figure 7. $(A)$ In vitro cleavage of high-molecular-weight kininogen (HK) by exposure of plasma to kaolin as shown in a Western blot using anti-highmolecular-weight kininogen antibodies. The 120-kilodalton (kDa) band across all Lewis and Buffalo plasma lanes but not in the kininogendeficient brown Norway (BN) rat plasma lane represents high-molecularweight kininogen (120 kilodaltons). The broad bands localized just below the 83-kilodalton standard across all lanes indicate T-kininogen (TK) and albumin (alb.). The band situated above the 44-kilodalton standard marked across activated samples (3, 6, and 15 minutes) from both Lewis and Buffalo rats but not present in unactivated lanes ( 0 time point) or in the brown Norway lane represents the heavy chain of high-molecularweight kininogen (HC-HK; 62 kilodaltons). The delicate band localized just below the 44-kilodalton standard in Lewis and Buffalo plasma samples (but not in the brown Norway lane) represents the light chain of highmolecular-weight kininogen (LC-HK; 41 kilodaltons). The delicate band situated just above the 32-kilodalton standard across all lanes represents a nonspecific reaction with alkaline phosphatase (alk. phos.; 32 kilodaltons) that hydrolyzes BCIP/NBT phosphate substrate used to develop the color. Lane 1, plasma from a brown Norway rat (Katholiek strain) that is deficient in high-molecular-weight kininogen. Lane 2, plasma from Lewis rats before kaolin exposure. Lanes 3-5, Lewis rat plasma 3, 6, and 15 minutes after kaolin activation (note appearance of the 41- and 62-kilodalton cleavage product). Lane 6, Buffalo rat plasma with no kaolin. Lanes 7-9, plasma samples from Buffalo rats 3,6 , and 15 minutes after kaolin exposure. Mr, molecular weight. This Western blot is representative of three separate experiments. $(B)$ In vitro kallikrein generation in Lewis $(\bigcirc)$ and Buffalo $(\bullet)$ plasma activated by kaolin at the time intervals shown. Kallikrein activity is expressed as a hydrolysis of chromogenic substrate S-2302 (in micromoles per minute). The values are the mean of triplicate determinations at each time point. 
Table 2. Consumption of High-Molecular-Weight Kininogen After Kaolin Activation of Plasma From Lewis and Buffalo Rats

\begin{tabular}{lcccc}
\hline & \multicolumn{4}{c}{ Densitometry values at intervals after activation } \\
\cline { 2 - 5 } & $\begin{array}{c}0 \text { min } \\
(\mathrm{n}=3)\end{array}$ & $\begin{array}{c}3 \text { min } \\
(\mathrm{n}=2)\end{array}$ & $\begin{array}{c}6 \text { min } \\
(\mathrm{n}=2)\end{array}$ & $\begin{array}{c}15 \text { min } \\
(\mathrm{n}=3)\end{array}$ \\
\hline Lewis rats & $100^{a}$ & 96.5 & 61.5 & $34.0 \pm 8.7^{b}$ \\
Buffalo rats & 100 & 90.0 & 90.5 & $76.6 \pm 8.8$ \\
\hline
\end{tabular}

${ }^{a}$ Mean percent of control ( 0 minutes) value.

${ }^{b} P<0.05$ vs. Buffalo rat values. Values are expressed as mean \pm SEM.

krein activity decreased to $71 \%$ of maximal values in samples after 6 minutes of activation and to $57 \%$ and $51 \%$ after 15 minutes of activation in Lewis and Buffalo rat plasma, respectively. This decrease in activity has been shown to be caused by the naturally occurring plasma inhibitors $\mathrm{C} 1$ inhibitor and $\alpha_{2}$-macroglobulin. ${ }^{46}$ This assay indicates that, after exposure to kaolin, similar conversion of prekallikrein to kallikrein occurs in Lewis and Buffalo plasma and that inhibitor activity is similar in the two rat strains.

The decreased rate of cleavage of high-molecularweight kininogen after kaolin activation could be caused by slower formation of kallikrein, which depends on the rate of autoactivation by the surface of factor XII, the rate of activation of prekallikrein to kallikrein by factor XIIa, the rate of inhibition of kallikrein by plasma protease inhibitors, or the efficiency of cleavage of HK by plasma kallikrein. We have excluded the first three of these possibilities by showing no difference in the rate of kallikrein formation and its inactivation in plasma after exposure to kaolin in plasma from the rat strains.

\section{In Vitro Activation of Kininogen by Plasma Kallikrein}

Because the rates of kallikrein formation and inhibition were similar in Lewis and Buffalo rats, we considered that the relative resistance of Buffalo rat plasma high-molecular-weight kininogen to cleavage may be caused by an intrinsic difference in the high-molecularweight kininogen molecule. To test this hypothesis, we examined the cleavage of rat plasma high-molecularweight kininogen by purified plasma kallikrein. As shown in Figure 8, after exposure to kallikrein, the Lewis rat plasma high-molecular-weight kininogen is cleaved more rapidly than the Buffao rat plasma, as judged by a decrease in the high-molecular-weight kininogen band at as early as 6 minutes and more dramatically at 15 minutes. In addition, the high-chain high-molecular- weight kininogen cleavage product is evident in the Lewis rat plasma at 3 minutes but is not apparent in the Buffalo plasma until 6 minutes. Similar results were found in five separate experiments. These data, together with our results in Figure 7, argue for an intrinsic defect in high-molecular-weight kininogen to explain the defective cleavage by kallikrein.

\section{Discussion}

The rat model of chronic, granulomatous enterocolitis induced by intramural injection of PG-APS has several unique features that enhance its relevance to Crohn's disease. First, active inflammation persists for at least 4 months, which is considerably longer than other rodent models of induced enterocolitis. ${ }^{47}$ Colitis induced by trinitrobenzene sulfonic acid and ethanol resolves by $4-6$ weeks, and granulomas are not a consistent feature. ${ }^{48}$ Although colonic inflammation persists for at least 6 months in interleukin 2, interleukin 10 , and T-cell receptor knockout mice,${ }^{49-51}$ for up to 12 months in HLAB27/ $\beta_{2}$-microglobulin transgenic rats ${ }^{52}$ (R. B. Sartor, unpublished data, March 1996), and for several years in cotton-topped tamarins, ${ }^{53}$ inflammation is largely confined to the mucosa in these models rather than to the transmural pattern of PG-APS-induced inflammation. ${ }^{3,4,47,49-51}$ Second, enterocolitis after PG-APS injection spontaneously reactivates at a predictable time point. Third, intestinal injury is associated with multiorgan systemic inflammation, including arthritis, hepatic granulomas, splenic inflammation, anemia, and leukocytosis.

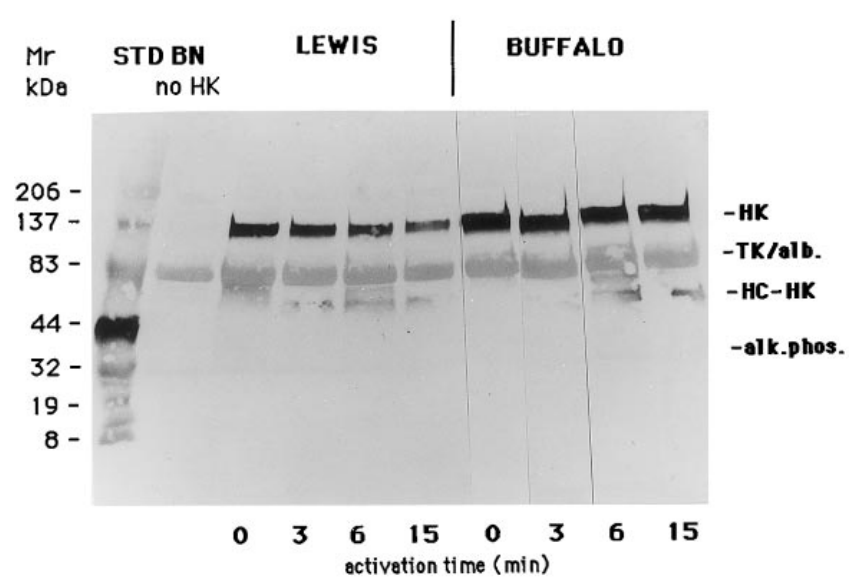

Figure 8. In vitro cleavage of high-molecular-weight kininogen (HK) in Lewis and Buffalo rat plasma after activation by purified human plasma kallikrein $(0.2 \mu \mathrm{mol} / \mathrm{L})$. Representative rat plasma samples are either unactivated ( 0 time) or activated by kallikrein. The labeling of the lines is the same as in Figure 7A. This Western blot is representative of five separate experiments. kDa, kilodaltons; Mr, molecular weight. 
Periportal hepatic inflammation has been described in $4 \%$ of cotton-top tamarins with colitis (B. F. Warren, unpublished data, June 1995), a frequency much less than the $73 \%$ incidence in PG-APS-injected Lewis rats examined during the chronic phase of inflammation. Fourth, PG-APS-induced enterocolitis follows different kinetics and patterns of inflammation in selected inbred rat strains. Finally, in this model, inflammation is induced by an environmentally relevant substance. PG-PS is found in high concentrations within the lumina of the distal ileum and colon, and cell wall polymers isolated from normal luminal bacteria can induce chronic inflammation. ${ }^{6-8}$

Lewis rats showed spontaneous reactivation of intestinal inflammation after a single intramural injection of PG-APS. This represents a true reactivation of enterocolitis rather than persistence of acute inflammation, as indicated by the biphasic course of the inflammatory response. Acute gut injury in the Lewis rats peaked 1-5 days after PG-APS injection by gross, histological, and biochemical parameters, was relatively quiescent by 8 days, and dramatically increased around 14 days after a single PG-APS injection. Reactivation is further documented by higher gross and histological inflammatory scores during chronic phases of inflammation compared with acute values. Whether individual rats undergo multiple exacerbations and remissions of enterocolitis analagous to the relapsing and remitting course of arthritis in Sprague-Dawley rats after intraperitoneal PG-APS injection ${ }^{6}$ is difficult to determine because we measured gut injury only at the time of necropsy. However, arthritis after intramural intestinal injection shows a progressive course with onset approximately 14 days after PGAPS injection, in contrast to the biphasic course of arthritis in Lewis rats after intraperitoneal PG-APS injection. ${ }^{6,9,20}$ Of note, the incidence and kinetics of granulomatous hepatitis and anemia are similar in Lewis rats injected intraperitoneally or subserosally with PGAPS. ${ }^{10,11,20}$ Previous studies in the subserosal PG-APS Lewis rat model have only evaluated single time points during acute and chronic phases and have not documented spontaneous reactivation of inflammation. ${ }^{4,5}$ In preliminary studies, we have incriminated T-lymphocytes in the pathogenesis of the chronic, relapsing phase of intestinal and systemic inflammation in Lewis rats after intramural PG-APS injection. ${ }^{54}$

This study clearly shows a differential host genetic susceptibility to bacterial cell wall polymers in inbred rat strains. Lewis rats developed chronic, granulomatous enterocolitis with fibrosis and extraintestinal inflammation, whereas Buffalo rats showed a self-limited course of acute intestinal inflammation, anemia, and leukocytosis with no evidence of spontaneous relapse of enterocolitis, very little fibrosis, and no arthritis or hepatic granulomas. Paradoxically, Buffalo rats had a slightly greater degree and a more protracted course of acute intestinal inflammation than Lewis rats. We have shown previously that Fischer $\mathrm{F}_{344}$ rats develop only self-limited acute enterocolitis without extraintestinal inflammation after intramural PG-APS administration ${ }^{4}$ or subcutaneous indomethacin. $^{13}$ Similar differential genetic susceptibilities in inbred rat strains are observed in arthritis and hepatic granulomas after intraperitoneal injection of PGAPS $^{6,9,10}$ and hepatobiliary inflammation associated with experimental small bowel bacterial overgrowth. ${ }^{14}$ In preliminary studies, $\mathrm{C}_{3} \mathrm{H} / \mathrm{HeJ}$ or $\mathrm{C}_{3} \mathrm{H} / \mathrm{HeN}$ strain mice are high responders to experimental enterocolitis, such as Tcell receptor knockout, ${ }^{51}$ trinitrobenzene sulfonic acid, ${ }^{55}$ and Citrobacter freundii ${ }^{56}$-induced colitis, whereas DBA/ 2 and C57/BL mice are low responders. ${ }^{51,55,56}$

Our results show that responsiveness to activation of the contact system may be one of the determinants of genetic susceptibility to chronic, relapsing intestinal and systemic inflammation. Even during the acute phase of gut inflammation ( 5 days after PG-APS injection), when Buffalo rats showed a greater degree of inflammation than Lewis rats, there was no consumption of plasma prekallikrein and high-molecular-weight kininogen in Buffalo rats, in contrast to significant decreases in these precursor molecules in Lewis rats. Evidence of activation of the contact system persisted 24 days and 6 weeks after PG-APS injection in Lewis rats, corresponding to early phases and midphases of chronic enterocolitis, respectively. Moreover, there was decreased cleavage of highmolecular-weight kininogen in plasma from Buffalo rats in response to in vitro activation, indicating an intrinsic difference in activation of the contact system in the differentially susceptible rat strains. Because the activation of prekallikrein to kallikrein and the inhibition of kallikrein by plasma protease inhibitors were similar, the defect seemed to be localized to the high-molecular-weight kininogen molecule. This conclusion was supported by a direct demonstration that purified plasma kallikrein cleaves high-molecular-weight kininogen in Lewis plasma more rapidly than in Buffalo plasma. The nature of the resistance of Buffalo rat high-molecular-weight kininogen to cleavage is unknown; potential mechanisms include protein polymorphism or posttranslational modifications such as glycosylation. The reproducible difference in high-molecular-weight kininogen cleavage in vitro by kallikrein is compelling because there is evidence for prekallikrein activation in vivo (significant decrease 
in functional prekallikrein) in Lewis but not in Buffalo rats. The significance in the pathogenesis of experimental intestinal inflammation is not fully understood, but the efficacy of a kallikrein inhibitor ${ }^{57}$ in PG-PS-induced enterocolitis in Lewis rats speaks for an important contribution by the contact system. In addition, this pathway may be important in other tissues because experimental arthritis induced by PG-APS is also blocked by a kallikrein inhibitor. $^{21}$

Several other alterations in immunoresponsiveness have been postulated to determine host genetic susceptibility in Lewis rats to chronic inflammation. Our previous studies have shown an increased ratio of interleukin 1 messenger RNA to its endogenous inhibitor interleukin 1 receptor antagonist in chronically inflamed intestinal tissues of Lewis rats injected subserosally with PG-APS relative to acutely injured Fischer rats, but no difference was observed with Buffalo rats. ${ }^{4}$ Similarly, Sternberg et al. ${ }^{9}$ have shown defective hypothalamic production of corticotropin-releasing hormone in Lewis rats relative to Fischer rats in response to short-term systemic administration of interleukin 1 or PG-APS. Additionally, these investigators showed enhanced local production of corticotropin-releasing hormone and cyclooxygenase in the inflamed joints of Lewis rats after intraperitoneal PGAPS injection but no up-regulation of local corticotropin-releasing hormone or cyclooxygenase synthesis in noninflamed Fischer rats. ${ }^{58,59}$ These results can be criticized because Fischer rats fail to develop arthritis after intraperitoneal PG-APS injection; therefore, increased articular corticotropin-releasing hormone and cyclooxygenase production could be a consequence rather than the cause of the inflammatory response. In contrast, our current results show no evidence of activation of the contact system of Buffalo rats during a time of active intestinal inflammation and anemia, indicating that consumption of plasma prekallikrein and high-molecular-weight kininogen is not merely secondary to the inflammatory response. This interpretation is strongly supported by defective in vitro high-molecular-weight kininogen cleavage in activated plasma from normal Buffalo rats and inhibition of PG-APS-induced inflammation in Lewis rats by selective plasma kallikrein blockade. ${ }^{21,57}$

We have shown previously activation of the contact system during acute and chronic phases of systemic inflammation induced by intraperitoneal PG-APS injection in Lewis rats. ${ }^{20}$ Plasma functional high-molecular-weight kininogen concentrations inversely correlated with acute arthritis scores ( 5 days after intraperitoneal PG-APS injection). In contrast to the decrease in plasma high-molecular-weight kininogen values at 42 days after PG-APS injection in our current study, high-molecular-weight kininogen values in Lewis rats injected intraperitoneally with PG-APS were no different than those of control rats during chronic inflammation (23 and 45 days), ${ }^{20}$ although plasma prekallikrein concentrations were significantly decreased at all time points in both studies. Activation of the contact system in PG-APS-induced enterocolitis and systemic disease is similar to that observed in clinical sepsis ${ }^{60}$ typhoid fever, ${ }^{61}$ and Rocky Mountain spotted fever ${ }^{62}$ and in volunteers administered endotoxin (lipopolysaccharide). ${ }^{63}$ Thus, it is evident that the bacterial cell wall polymers lipopolysaccharide and PG-APS share the ability to activate the contact system in vivo. The preliminary observation that the contact system is activated in active ulcerative colitis ${ }^{64}$ is consistent with our findings in experimental enterocolitis. In a prospective study of Rocky Mountain spotted fever, the contact system was activated at the earliest stages, suggesting a pathogenic role in the inflammatory response. ${ }^{62}$ More convincing demonstrations of a causal role for the contact system in systemic inflammation is provided by attenuation of disseminated intravascular coagulation in experimental porcine gram-negative sepsis by recombinant $\alpha_{1}$-antitrypsin Pittsburgh ${ }^{65}$ and the ability of a monoclonal antibody to factor XII to block the late phase of hypotension and enhance survival in baboons infused with Escherichia coli. ${ }^{66}$

Active inflammation and tissue damage may be accompanied by complex alterations of zymogens and cofactors as a result of activation of the contact system. ${ }^{22}$ The observed decrease in plasma prekallikrein and high-molecular-weight kininogen levels in our rat model of granulomatous enterocolitis and systemic inflammation may be caused by consumption of precursor proteins as they are converted to active enzymes or cofactors or, alternatively, by changes in the rate of synthesis and degradation of these zymogens. Our results support contact activation with consumption of precursor proteins as the underlying process. The normal antithrombin III and factor XI levels shown during acute and chronic phases of inflammation make significant liver disease (i.e., decreased synthesis) much less likely.

Activation of kallikrein and bradykinin could induce intestinal injury in Lewis rats by several mechanisms. Kallikrein stimulates neutrophil aggregation and degranulation, ${ }^{25,26}$ which could contribute to the increased numbers of neutrophils in inflamed tissues during acute and chronic phases of enterocolitis induced by PG-APS, as documented by increased acute-phase histological scores and myeloperoxidase values. High-molecularweight kininogen serves as a cofactor for kallikrein for- 
mation, ${ }^{22}$ providing a potential mechanism by which a selective defect in high-molecular-weight kininogen activation in Buffalo rats could also inhibit kallikrein activation. In addition, a change in one amino acid, at or near the cleavage site on the Buffalo high-molecularweight kininogen for plasma kallikrein, would inhibit high-molecular-weight kininogen cleavage. Bradykinin could directly induce tissue edema in experimental enterocolitis by virtue of its ability to enhance vascular permeability ${ }^{22}$ and to stimulate arachidonic acid metabolites. ${ }^{67}$ Factor XIIa (cleaved by kallikrein) and bradykinin stimulate interleukin 1 production, ${ }^{68,69}$ and interleukin 1 dramatically up-regulates the ability of bradykinin to release arachidonic acid metabolites. ${ }^{67,69}$ Tissue concentrations of interleukin 1 messenger RNA and protein are increased during acute and chronic phases of PG-APSinduced enterocolitis and correlate with the degree of tissue injury. ${ }^{4}$

In summary, we describe a unique rat model of chronic, spontaneously relapsing, granulomatous enterocolitis with associated extraintestinal inflammation. This model can be used to investigate mechanisms of genetically determined host susceptibility to chronic intestinal inflammation, thereby providing new insights into the pathogenesis of Crohn's disease. Our demonstration of selective in vivo and in vitro activation of the contact system in genetically susceptible Lewis rats, correlation of plasma high-molecular-weight kininogen and plasma prekallikrein with chronic inflammation, and attenuation of intestinal $^{57}$ and systemic inflammation ${ }^{21}$ by specific kallikrein blockade suggest that the kallikrein/kinin pathway is integrally involved in the pathogenesis of granulomatous enterocolitis and associated systemic complications. These results provide a firm rationale for exploration of the contact system in Crohn's disease and a justification for attempts to block components of this system in experimental and clinical chronic intestinal inflammation.

\section{References}

1. Podolsky DK. Inflammatory bowel disease. N Engl J Med 1991; 325:928-937.

2. Sartor RB. Current concepts of the etiology and pathogenesis of ulcerative colitis and Crohn's disease. Gastroenterol Clin North Am 1995; 24:475-508.

3. Sartor RB, Cromartie WJ, Powell DW, Schwab JH. Granulomatous enterocolitis induced in rats by purified bacterial cell wall fragments. Gastroenterology 1985;89:587-595.

4. McCall RD, Haskil S, Zimmermann EM, Lund PK, Thompson RC, Sartor RB. Tissue interleukin-1 and interleukin-1 receptor antagonist expression in enterocolitis in resistant and susceptible rats. Gastroenterology 1994;106:960-972.

5. Yamada T, Sartor RB, Marshall S, Specian RD, Grisham MB.
Mucosal injury and inflammation in a model of chronic granulomatous enterocolitis. Gastroenterology 1993;104:759-771.

6. Schwab JH. Phlogistic properties of peptidoglycan-polysaccharaide polymers from cell walls of pathogenic and normal-flora bacteria which colonize humans. Infect Immun 1993;61:4535-4539.

7. Stimpson SA, Brown RR, Anderle SK, Klapper DG, Clark RL, Cromartie WJ, Schwab JH. Arthropathic properties of cell wall polymers from normal flora bacteria. Infect Immun 1986;51:240249.

8. Severijnen AJ, Hazenberg MP, Van de Merwe JP. Induction of chronic arthritis in rats by cell wall fragments of anaerobic coccoid rods isolated from the faecal flora of patients with Crohn's disease. Digestion 1988;39:118-125.

9. Sternberg EM, Hill JM, Chrousos GP, Kamilaris T, Listwak SJ, Gold PW, Wilder RL. Inflammatory mediator-induced hypothalamic-pituitary-adrenal activation is defective in streptococcal cell wall arthritis-susceptible Lewis rats. Proc Natl Acad Sci USA 1989; 86:2374-2378.

10. Wahl SM, Hunt DA, Allen JB, Wilder RL, Paglia L, Hunt AR. Bacterial cell wall-induced hepatic granulomas: an in vivo model of $T$ cell-dependent fibrosis. J Exp Med 1986;63:884-902.

11. Sartor RB, Anderle SK, Rifai N, Goo DA, Cromartie WJ, Schwab $\mathrm{JH}$. Protracted anemia associated with chronic, relapsing systemic inflammation induced by arthropathic peptidoglycan-polysaccharide polymers in rats. Infect Immun 1989;57:11771185.

12. Griffiths MM, DeWitt CW. Genetic control of collagen-induced arthritis in rats: the immune response to type II collagen among susceptible and resistant strains and evidence for multiple gene control. J Immunol 1984;132:2830-2836.

13. Sartor RB, Bender D, Holt LC. Susceptibility of inbred rat strains to intestinal and extraintestinal inflammation induced by indomethacin (abstr). Gastroenterology 1992;102:A690.

14. Lichtman SN, Sartor RB, Schwab JH, Keku J. Hepatic inflammation in rats with experimental small bowel bacterial overgrowth. Gastroenterology 1990; 98:414-423.

15. Davis JK, Thorp RB, Maddox PA, Brown MB, Cassell GH. Murine respiratory mycoplasmosis in $F_{344}$ and LEW rats: evolution of lesions and lung lymphoid cell populations. Infect Immun 1982; 36:720-729.

16. Khoury SJ, Hancock WW, Weiner HL. Oral tolerance to myelin basic protein and natural recovery from experimental autoimmune encephalomyelitis are associated with downregulation of inflammatory cytokines and differential upregulation of transforming growth factor, interleukin 4, and prostaglandin E expression in the brain. J Exp Med 1992;176:1355-1364.

17. Bristol LA, Durum SK, Eisenberg SP. Differential regulation of group A streptococcal peptidoglycan-polysaccharide (PG-APS)stimulated macrophage production of IL-1 by rat strains susceptible and resistant to PG-APS-induced arthritis. Cell Immunol 1993;149:130-143.

18. Lambris JD, Allen JB, Schwab JH. In vivo changes in complement induced with peptidoglycan-polysaccharide polymers from streptococcal cell walls. Infect Immun 1982;35:377-380.

19. Yoshino S, Cromartie WJ, Schwab JH. Inflammation induced by bacterial cell wall fragments in the rat air pouch: comparison of rat strains and measurement of arachidonic acid metabolites. Am J Pathol 1985;121:327-336.

20. DeLa Cadena RA, Laskin KJ, Pixley RA, Sartor RB, Schwab JH, Back N, Bedi GS, Fisher RS, Colman RW. Role of kallikrein-kinin system in pathogenesis of bacterial cell wall-induced inflammation. Am J Physiol 1991;260:G213-G219.

21. DeLa Cadena RA, Stadnicki A, Sartor RB, Kettner CA, Adam A, Colman RC. Inhibition of plasma kallikrein blocks the development of acute peptidoglycan-induced arthritis and anemia in the Lewis rat. FASEB J 1995; 9:446-452. 
22. DeLa Cadena RA, Wachtfogel YT, Colman RW. Contact activation pathway: inflammation and coagulation. In: Colman RW, Hirsch J, Marder VJ, Salzman EW, eds. Hemostasis and thrombosis: basic principles and clinical practice. Philadelphia: Lippincott, 1994:219-240.

23. Scott CF, Silver LD, Purdon AD, Colman RW. Cleavage of human high molecular weight kininogen by factor Xla in vitro. Effect on structure and function. J Biol Chem 1985;260:10856-10863.

24. Kaplan AP, Kay AB, Austen KF. A prealbumin activator of prekallikrein. J Exp Med 1972;135:81-97.

25. Schapira M, Despland E, Scott CF, Boxer LA, Colman RW. Purified human plasma kallikrein aggregates human blood neutrophils. J Clin Invest 1982;69:1199-1202.

26. Wachtfogel YT, Kucich UI, James HL, Scott CF, Schapira M, Zimmerman EM, Cohen AB, Colman RW. Human plasma kallikrein releases neutrophil elastase during blood coagulation. J Clin Invest 1983; 72:1672-1677.

27. Manning DC, Snyder SH, Kachur JF, Miller RJ, Field M. Bradykinin receptor-mediated chloride secretion in intestinal function. Nature 1982;299:256-259.

28. Schreiber G, Tsykin A, Aldred AR, Thomas T, Fung WP, Dickson PW, Cole T, Birch H, DeJong FA, Milland J. The acute phase response in the rodent. Ann NY Acad Sci 1989;557:61-86.

29. Simpson SA, Schwab JH. Chronic remittent erosive arthritis induced by bacterial peptidoglycan-polysaccharide structures. In: Chang JY, Lewis AJ, eds. Pharmacological methods in the control of inflammation. New York: Liss, 1989:381-394.

30. Dische A, Shettles LB. A specific color reaction of methyl pentoses and a spectrophotometric micromethod for their determination. J Biol Chem 1948;175:595-603.

31. Grisham MB, Benoit JN, Granger DN. Assessment of leukocyte involvement during ischemia and reperfusion of intestine. Meth Enzymol 1990;186:729-741.

32. Scott CF. Determination of Antithrombin III (AT-III) using the Coatest Antithrombin Kit and a microplate system. Ann NY Acad Sci 1985; 485:443-444.

33. DeLa Cadena RA, Scott CF, Colman RW. Evaluation of a microassay for human plasma prekallikrein. J Lab Clin Med 1987;109: 601-607.

34. Scott CF, Colman RW. A simple and accurate microplate assay for the determination of factor XI in plasma. J Lab Clin Med 1988; 111:708-714.

35. Proctor RR, Rapaport SJ. The partial thromboplastin time with kaolin: the simple screening test for the first stage plasma clotting deficiencies. Am J Clin Pathol 1961;36:212-219.

36. Colman RW, Bagdasarian A, Talamo RC, Scott CF, Seavey M, Guimaraes JA, Pierce JV, Kaplan AP. Williams trait. Human kininogen deficiency with diminished levels of plasminogen proactivator and prekallikrein associated with abnormalities of the Hageman factor-dependent pathways. J Clin Invest 1975;56:1650-1662.

37. Adam A, Damas J, Calay G, Renard C, Remacle-Volon GR, Bourdon V. Quantification of rat T-kininogen using immunological methods. Application to inflammatory processes. Biochem Pharmacol 1989;38:1569-1575.

38. Adam A, Damas J, Renard C, Calay G, Bourdon V. Purification and characterization of plasma T-kininogen from Wistar and brown Norway rats. Biochem Cell 1989;67:86-92.

39. Moreau T, Esnard F, Gutman N, Degand P, Gauthier F. Cysteineproteinase-inhibiting function of T kininogen and of its proteoIytic fragments. Eur J Biochem 1988;173:185-190.

40. Tijssen P. Practice and theory of enzyme immunoassays. In: Burton $\mathrm{RH}$, Von Knippenberg PH, eds. Laboratory techniques in biochemistry and molecular biology Amsterdam: Elsevier, 1985: 238.

41. Hjelm H, Hjelm K, Sjöquist. Protein A from Staphylococcus aureus: its isolation by affinity chromatography and its use as an immunosorbent for isolation of immunoglobulins. J FEBS Lett 1972;28:73-76.

42. Hock J, Vogel R, Linke RP, Muller-Esterl W. High molecular weight kininogen-binding site of prekallikrein probed by monoclonal antibodies. J Biol Chem 1990;265:12005-12011.

43. Page JD, Colman RW. Localization of distinct functional domains on prekallikrein for interaction with both high molecular weight kininogen and activated XII in a $28-\mathrm{kDa}$ fragment (amino acids 141-371). J Biol Chem 1991;266:8143-8148.

44. Laemmli UK. Cleavage of structural proteins during the assembly of the head of bacteriophage T4. Nature 1970;227:680-685.

45. Tallarida RJ, Murray RG. Manual of pharmacologic calculations with computer programs. New York: Springer-Verlag, 1987:121.

46. Colman RW, Mattler I, Sherry S. Studies of the kallikreinogenkallikrein enzyme system of human plasma. II. Evidence relating the kaolin-activated arginine esterase to plasma kallikrein. J Clin Invest 1969;48:23-32.

47. Elson CO, Sartor RB, Tennyson G, Riddel R. Experimental models of IBD. Gastroenterology 1995;109:1344-1367.

48. Morris GP, Beck PL, Herridge MS, Depew WT, Szewczuk MR, Wallace JL. Hapten-induced model of chronic inflammation and ulceration in the rat colon. Gastroenterology 1989;96:795-803.

49. Sadlack B, Merz H, Schorle H, Schimpl A, Feller AC, Horak I. Ulcerative colitis-like disease in mice with a disrupted interleukin2 gene. Cell 1993; 75:253-261.

50. Kuhn R, Lohler J, Rennick D, Rajowsky K, Muller W. Interleukin10-deficient mice develop chronic enterocolitis. Cell 1993; 75: 263-279.

51. Mombaerts P, Mizoguchi E, Grusby M, Glimcher LH, Bhan AK, Tonegawa S. Spontaneous development of inflammatory bowel disease in T cell receptor mutant mice. Cell 1993;63:1099 1112.

52. Hammer RE, Richardson JA, Simmons WA, White AL, Breban M, Taurog JD. High prevalence of colorectal cancer in HLA-B27 transgenic $F_{344}$ rats with chronic inflammatory bowel disease. J Invest Med 1995;43:262-268.

53. Madara JL, Podolsky DK, King NW, Sehgal PK, Moore R, Winter HS. Characterization of spontaneous colitis in cotton-top tamarins (Saguinus oedipus) and its response to sulfasalazine. Gastroenterology 1985;88:13-19.

54. Sartor RB, Bender DE, Allen JB, Zimmerman EM, Holt LC, Pardo MS, Lund PK, Wahl SM. Chronic experimental enterocolitis and extraintestinal inflammation are T lymphocyte dependent (abstr). Gastroenterology 1993;104:808A.

55. Beagley KW, Black CA, Elson CO. Strain differences in susceptibility to TNBS-induced colitis (abstr). Gastroenterology 1991; 100:560A.

56. Barthold SW, Osbaldiston GW, Jonas AM. Dietary, bacterial, and host genetic interactions in the pathogenesis of transmissible murine colonic hyperplasia. Lab Anim Sci 1977;27:938-945.

57. Stadnicki A, DeLa Cadena RA, Kettner C, Sartor RB, Bender DA, Kettner CA, Rath HC, Adam A, Colman RW. A selective plasma kallikrein inhibitor attenuates acute enterocolitis in the Lewis rat. Dig Dis Sci (in press).

58. Sano H, Hla T, Maier JAM, Crofford L, Case JP, Maciag T, Wilder $\mathrm{RL}$. In vivo cyclooxygenase expression in synovial tissues of patients with rheumatoid arthritis and osteoarthritis and rats with adjuvant and streptococcal cell wall arthritis. J Clin Invest 1992; 89:97-108.

59. Crofford LG, Sano H, Karalis K, Webster EL, Goldmuntz EA, Chrousos GP, Wilder RL. Local secretion of corticotropin-releasing hormone in the joints of Lewis rats with inflammatory arthritis. J Clin Invest 1992;90:2555-2564.

60. Mason JW, Kleeberg U, Dolan P, Colman RW. Plasma kallikrein and Hageman factor in gram-negative bacteremia. Ann Intern Med 1979;73:545-551. 
61. Colman RW, Edelman R, Scott CF, Gilman RH. Plasma kallikrein activation and inhibition during typhoid fever. J Clin Invest 1978; 61:287-296.

62. Rao AK, Schapira M, Clements ML, Niewiarowski S, Budzynski AZ, Schmaier AH, Harpel PC, Blackwelder WC, Scherrer JR, Sobel E, Colman RW. A prospective study of Rocky Mountain spotted fever. N Engl J Med 1988;318:1021-1028.

63. DeLa Cadena RA, Suffredini AF, Page JD, Pixley RA, Kaufman N, Parrillo JE, Colman RW. Activation of the kallikrein-kinin system after endotoxin administration to normal human volunteers. Blood 1993;81:3313-3317.

64. Stadnicki A, Niewiarowski T, DeLa Cadena RA, Colman RW. Activation of the contact system and circulating neutrophil elastase in the ulcerative colitis patient (abstr). World Cong Gastroenterol 1994:1116.

65. Colman RW, Flores DN, DeLa Cadena RA, Scott CF, Cousens L, Barr PJ, Hoffman IB, Kueppers F, Fisher D, Idell S. Recombinant alpha 1-antitrypsin Pittsburgh attenuates experimental gramnegative septicemia. Am J Pathol 1988;130:418-426.

66. Pixley RA, DeLa Cadena RA, Page JD, Kaufman N, Wyshock EG, Change A, Taylor FB Jr, Colman RW. The contact system contributes to hypotension but not disseminated intravascular coagulation in lethal bacteremia: in vivo use of a monoclonal anti-factor XII antibody to block contact activation in baboons. J Clin Invest 1993;91:61-68.
67. Angel J, Audubert F, Bismuth G, Fournier C. IL-1 beta amplifies bradykinin-induced prostaglandin E2 production via a phospholipase D-linked mechanism. J Immunol 1994;152:5032-5040.

68. Toossi Z, Sedor JR, Mettler MA, Everson B, Young T, Ratnoff OD. Induction of expression of monocyte interleukin 1 by Hageman factor (factor XII). Proc Natl Acad Sci USA 1992;89:1196911972.

69. Burch RM, Connor JR, Tiffany CW. The kallikrein-kininogen-kinin system in chronic inflammation. Agents Actions 1989;27:258260.

Received June 23, 1995. Accepted January 10, 1996.

Address requests for reprints to: R. Balfour Sartor, M.D., Division of Digestive Diseases, CB\#7080, University of North Carolina at Chapel Hill, Chapel Hill, North Carolina 27599-7080. Fax: (919) 966-6842.

Supported in part by grants DK40249 (to R.B.S.), DK43735 (to R.W.C.), and DK34987 (to R.B.S.) from the U.S. Public Health Service; by a Clinical Investigator Award HL02681 (to R.A.C.); and by the Crohn's and Colitis Foundation of America.

Drs. Sartor and DeLa Cadena contributed equally to this paper.

The authors thank Brian Springer and Rita Stewart for skillful manuscript preparation and Roger Brown, Lisa Holt, and Diane Bender for expert technical support. 